\title{
Developing an Interactive Data Visualization Platform to Present the Adaption of Electrical Vehicles in Washington, California and New York
}

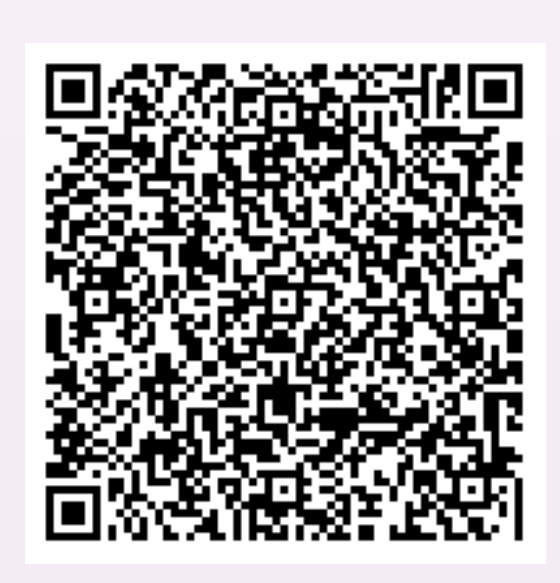

\section{Hiba Ayad, Muna Al-Obadi, Lana Al-Kilani, Haneen Hussein , Raiha Arshad Supervisor: Dr. Murat Kucukvar}

\section{Abstract}

This paper is an overview of using data visualization tools to provide a better insight into a large amount of data and represent the data in a visualized form. The used data is related to Electric Vehicles (EV) usage in three different states in the USA which are California, New York, and Washington. the data collected from reliable resources to assure the reliability and accuracy of the results, then compiled as a Microsoft Excel workbook which used as a data recourse in Microsoft Power BI. By visualizing the data we will end up with rich visuals which will clarify the data for the end-user. After analyzing the data, a clear vision created and recommendations have been suggested.
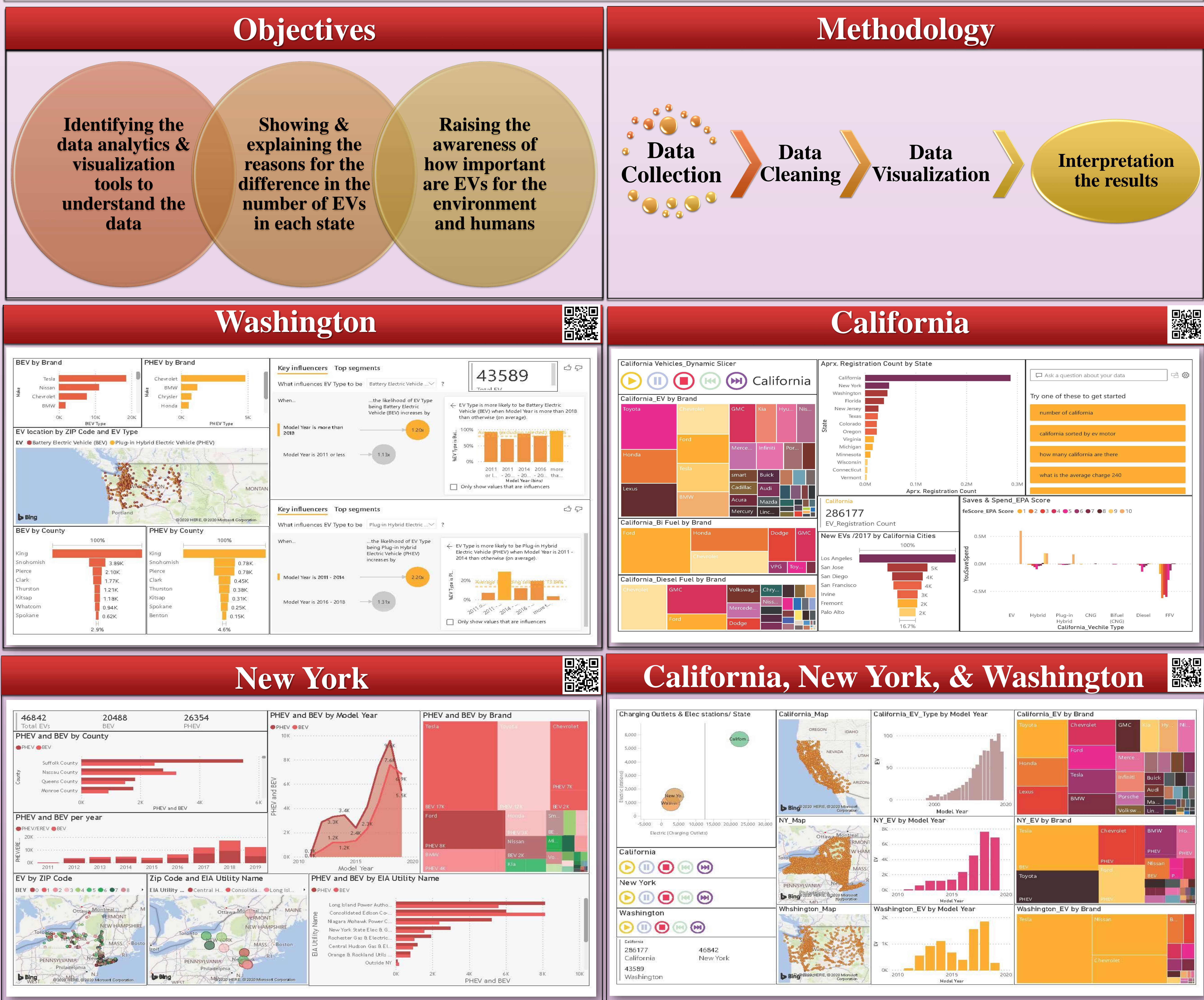

\section{California, New York, \& Washington}

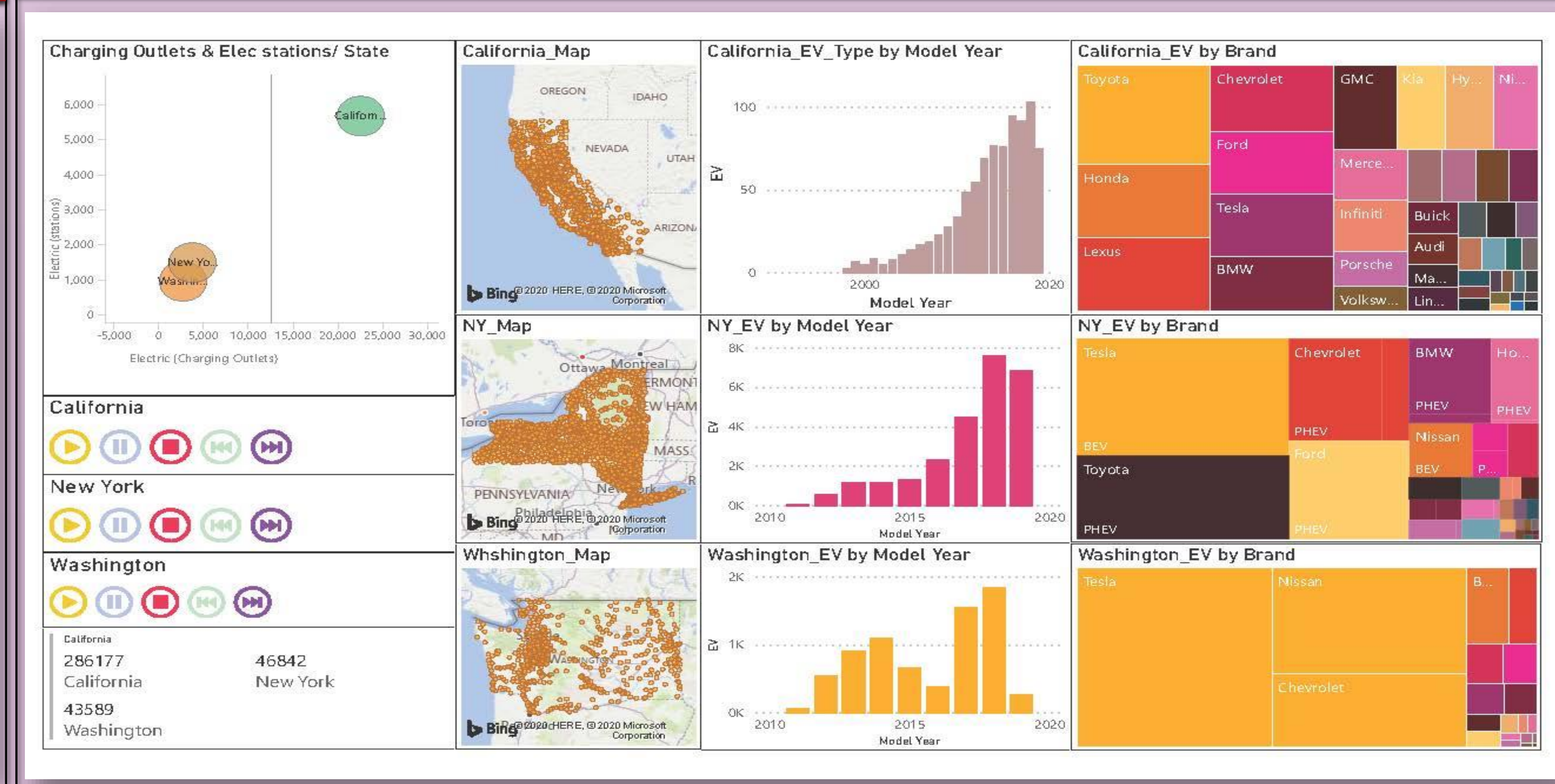

\section{Conclusion}

This research aims to perform visualization of electric vehicle data in the United States using the data visualization method.

The main outcomes summarized as the following:

- California's own has the highest number of EVs.

- Toyota, Tesla, and Chevrolet are the most widespread brands for EVs in the three states.

- In WA state we will find that there is a split for around 2 BEV for every 1 PHEV, but the PHEV started to slightly increase more at the end of Dec. 2017.

- The number of electric stations and charging outlets is consistent with the quantity of EVs in each state.

According to the obtained results, the USA has a future vision for having a sustainable environment as the country is planning on increasing the number of EVs to reduces the amount of GHG emission and fossil fuel. Moreover, there are more investments by the country to improving vehicle technology.

\section{References}

- N. Onat, M. Kucukvar, and O. Tatari, “Towards Life Cycle Sustainability Assessment of Alternative Passenger Vehicles,” Sustainability, vol. 6, no. 12, pp. 9305-9342, Dec. 2014, doi: 10.3390/su6129305.

- J. Kim, G. M. Abdella, S. Kim, K. N. Al-Khalifa, and A. M. Hamouda, “Control charts for variability monitoring in high-dimensional processes," Comput. Ind. Eng., vol. 130, pp. 309-316, Apr. 2019, doi:

10.1016/j.cie.2019.02.012

B. Phev, "Plug-in Electric Vehicle Registrations," 2013. 